\title{
Proximal, Tracheal, and Alveolar Pressures during High-Frequency Oscillatory Ventilation in a Normal Rabbit Model
}

\author{
DALE R. GERSTMANN, JANIE M. FOUKE, DEAN C. WINTER, A. FLORENTINA TAYLOR, AND \\ ROBERT A. DELEMOS
}

\author{
Southwest Foundation for Biomedical Research, San Antonio, Texas 78228 [D.R.G., A.F.T., R.A.d.L.]; \\ Department of Biomedical Engineering, Case Western Reserve University, Cleveland, Ohio 44106 [J.M.F.]; and \\ Southwest Research Institute, San Antonio, Texas 78284 [D.C.W.]
}

\begin{abstract}
To study the effect of different high-frequency oscillatory ventilation parameters on airway pressure, we measured oscillatory pressure amplitude $\left(\left|\mathbf{P}_{a w}\right|\right)$ and mean airway pressure $\left(\overline{\mathbf{P}}_{\mathrm{aw}}\right)$ at three sites in openchested normal rabbits: proximal, trachea, and alveolus. Five animals were studied to test a new pleural capsule design, which was then used in two groups of animals to measure right upper $(n=4)$ or middle $(n=5)$ lobe alveolar pressures. Animals were randomly sequenced through combinations of frequency $(10,15$, and $20 \mathrm{~Hz})$ and fractional inspiratory time $\left(T_{i}\right)(0.3$ and 0.5$)$ while normoxic and eucapnic. During capsule testing, we noted that alveolar pressures increased $(p<0.05)$ with increasing capsule mass, suggesting that compressive forces from the capsule may alter the capsule measurement. We thus used a lowmass $(430 \mathrm{mg}$ ) transducer system in the rabbit high-frequency oscillatory ventilation experiments. Using multifactorial analysis of variance, we found significant main effects of $T_{i}$ on $\overline{\mathbf{P}}_{\mathrm{aw}}$, and of measurement site on both $\left|\mathbf{P}_{\mathrm{aw}}\right|$ and $\overline{\mathbf{P}}_{\mathrm{aw}}$ (all $\left.p<0.009\right)$. Frequency did not influence variations in either $\left|P_{a w}\right|$ or $\overline{\mathbf{P}}_{\mathrm{aw}}$. For both $\mathrm{T}_{i}$ settings, alveolar upper lobe $\overline{\mathbf{P}}_{\mathrm{aw}}$ was lower compared with that of the middle lobe $(p<0.0005)$. Lengthening $T_{i}(0.3$ to 0.5$)$ increased tracheal $\overline{\mathbf{P}}_{\mathrm{aw}}$ in each capsule group $(p<0.0005)$. At $\mathrm{T}_{\mathrm{i}}=0.5$, tracheal $\overline{\mathbf{P}}_{\mathrm{aw}}$ exceeded $\overline{\mathrm{P}}_{\mathrm{aw}}$ measured proximally $(p<0.05)$. Our data support in vivo alveolar $\overline{\mathbf{P}}_{\mathrm{aw}}$ inhomogeneity and demonstrate significant changes in pressures within the lung related to $T_{i}$ during high-frequency oscillatory ventilation. (Pediatr Res 28: 367-373, 1990)
\end{abstract}

\section{Abbreviations}

HFOV, high-frequency oscillatory ventilation

$T_{i}$, fractional inspiratory time

$\overline{\mathbf{P}}_{\mathrm{aw}}$, mean airway pressure

$\left|\mathbf{P}_{\mathrm{aw}}\right|$, airway pressure amplitude

Characterization of airway pressure phenomena at the level of the alveolus during high-frequency ventilation has been investigated directly using alveolar capsule measurements (1-6) and indirectly with plethysmography or occlusion equilibrium pressure methodology $(7,8)$. Only two of these reports $(1,6)$ involve direct pressure measurements in an in vivo system. As a result,

Received May 16, 1989; accepted May 18, 1990.

Correspondence: Dale R. Gerstmann, M.D., Southwest Foundation for Biomedical Research, P.O. Box 28147, San Antonio, TX 78284.

Supported in part by Pediatric SCOR Grant HL 36536 from the National Heart, Lung, and Blood Institute. there are limited data on the relationship between proximal, tracheal, and alveolar pressures under conditions simulating clinical high-frequency applications.

However, multiple in vitro studies from several laboratories have provided useful information about high-frequency pulmonary mechanics. These experiments using excised dog lungs (2, $4,5,9-11$ ) have identified high-frequency related phenomena, including asynchronous alveolar filling, alterations in the distribution of ventilation, and heterogeneity of both alveolar mean pressure and alveolar pressure amplitude. Although these in vitro results provide some answers concerning the nature of gas flow and distribution during high-frequency ventilation, they do not address the nature of pulmonary pressure distribution under physiologic conditions. Our present research is directed at characterizing a pulmonary pressure profile in an in vivo model with normal gas exchange during HFOV at different parameters of frequency and $T_{i}$.

Because recent reports have also indicated that the pressures in the alveolar spaces may actually be higher than those measured in the trachea or large airways during some modes of highfrequency ventilation $(2-4,9,10,12,13)$, accuracy in measuring alveolar pressure has become very important. Additionally, the use of a small animal model is highly desirable, as application of HFOV strategies frequently involves the human neonate $(14$, 15). We have thus taken advantage of the recent development of a fiberoptic, catheter-tipped pressure transducer and have combined this technology with a design for a low-mass miniaturized pressure chamber to create a modified pleural capsule. We have evaluated this new capsule system in vitro and in vivo in a small animal model, and include that evaluation in this report.

Our other experiments use this capsule system in combination with a specialized tracheal pressure monitoring tube and standard pressure monitoring in the ventilator circuit to evaluate proximal, tracheal, and alveolar airway pressures during use of a clinical high-frequency oscillatory ventilator in animals with normal lungs. In this report, we explore the relationships of $T_{i}$, frequency, and airway measurement site on $\left|\mathrm{P}_{\mathrm{aw}}\right|$ and $\overline{\mathrm{P}}_{\mathrm{aw}}$.

\section{MATERIALS AND METHODS}

Pressure Measurement Systems. Transducer/capsule. Each capsule (Gesco International, Inc., San Antonio, TX) was constructed from 1-mm thick thermoplastic. The internal dimensions of the cylindrical capsule were a diameter of $2.9 \mathrm{~mm}$ and a height of $3.9 \mathrm{~mm}$. Total capsule internal volume was $23 \mu \mathrm{L}$. A $1-\mathrm{mm}$ flange around the outer circumference served as a bonding surface to the lung, providing $0.404 \mathrm{~cm}^{2}$ of area. A small hole $(0.07 \mathrm{~mm})$ was drilled in the top of the capsule to allow the introduction of a 27-gauge needle to pierce the pleural surface. The capsule was sealed to the lung with cyanoacrylate (Krazy 
Glue, Kiasca, IL), which was applied using a syringe and a 24gauge angiocatheter for maximum flow control of the adhesive. Three punctures were made through the pleura using a marked needle so that the puncture depth was uniformly $1.7 \mathrm{~mm}$, allowing pressure equilibration between the alveoli and the chamber. The top hole in the capsule was then sealed with rubber cement. A port in the side of the capsule $(1.35 \mathrm{~mm}$ inner diameter) was used to introduce the $4 \mathrm{~F}$ fiberoptic catheter-tipped pressure transducer (model 420, Camino Inc., San Diego, CA) into the capsule cavity. Rubber cement was also used to seal this port and to secure the transducer to the chamber.

The capsule mass was $129 \pm 5 \mathrm{mg}$ (mean $\pm \mathrm{SD}, n=5$ ). With the fiberoptic catheter transducer inserted into the capsule, the total mass of the alveolar pressure sensor unit was $430 \mathrm{mg}$. The low-mass capsule and transducer are shown in Figure 1.

The pressure-sensitive component in the fiberoptic catheter pressure transducer is a deformable membrane in a small cavity at the tip of the catheter. The outside surface of the deformable membrane is exposed to the pressure in the surrounding media. The catheter contains two optical fiber bundles. Light is transmitted through one fiber bundle and shone on the polished inside surface of the deformable membrane. Reflected light returns through the second fiber bundle to a signal detection and processing unit. Within this unit, light is detected and the intensity of reflected light is converted to a voltage that is proportional to the gauge pressure on the deformable membrane.

The frequency response of the transducer/capsule system was evaluated using the techniqes of Jackson and Vinegar (16). Calibration signals for the capsule system, the tracheal airway pressure measurement tube (described below), and a reference transducer (model 239, Setra Systems, Inc., Acton, MA) were compared using a frequency spectrum waveform analyzer (model 3682A, Hewlett-Packard Co., Palo Alto, CA) and a random frequency driver. The transfer functions of the reference and each test transducer system were compared. For the capsule system, an in situ calibration was also performed. The capsule opening was covered with tape to simulate a pleural surface and the tape punctured three times with a 27 -gauge needle. This in situ system was then compared with the reference transducer.

In vivo protocol. Five New Zealand White rabbits were anesthetized with an intramuscular injection of a mixture containing $3 \mathrm{mg} / \mathrm{kg}$ of xylazine, $1.5 \mathrm{mg} / \mathrm{kg}$ of acepromazine, and $30 \mathrm{mg} / \mathrm{kg}$ of ketamine. An arterial line was placed in the ear and used for extraction of blood gases. Similarly, an ear vein was cannulated for administration of i.v. fluids and medications. The animals were intubated via a tracheostomy with a $3.0-\mathrm{mm}$ outer diameter endotracheal tube, paralyzed with $0.2 \mathrm{mg} / \mathrm{kg}$ pancuronium bromide i.v., and ventilated with a high-frequency oscillatory ventilator (model 3200, SensorMedics, Dayton, OH). The animals continued to receive i.v. pancuronium bromide and ketamine $(10 \mathrm{mg} / \mathrm{kg})$ throughout the experiment.

When the rabbit was stable, a right thoracotomy was performed. The low-mass pleural capsule was applied to the central portion of the right middle lobe after a calibration check of the fiberoptic transducer. Once the capsule was in place, signal integrity was verified by observation of the capsule pressure waveform.

Tracheal pressures were measured using a $\pm 100 \mathrm{~cm} \mathrm{H}_{2} \mathrm{O}$ pressure transducer (model MP45, Validyne Engineering Corp., Northridge, CA), which was connected to a 12-cm, 18-gauge stainless steel tube using a Luer stub and $5 \mathrm{~cm}$ of stiff plastic tubing. The stainless steel pressure-monitoring tube was fastened to the endotracheal tube and had a 25-gauge side port placed perpendicular to the trachea $2 \mathrm{~cm}$ below the distal opening of the endotracheal tube. Calibrations of both the alveolar and tracheal transducer systems could be statically verified by interrupting HFOV for a few seconds, allowing tracheal and alveolar pressure to equilibrate to the same mean pressure.

Pressure waveform signals were recorded without filtering at a sampling rate of 500 samples/s using a laboratory computer (model 500, MASSCOMP, Westford, MA). For each data set, values of peak, trough, and mean airway pressures were averaged over three oscillations. Pressure amplitude was calculated as the difference between peak and trough airway pressures.

The effect of increased capsule mass on measured pressures was evaluated by attaching calibrated weights to the top of the right middle lobe capsule. One- and $2-\mathrm{g}$ weights were added to increase the system mass to $1.4 \mathrm{~g}$ and $2.4 \mathrm{~g}$, respectively. Three to four data sets were collected at baseline (no added weight), after addition of each calibrated weight, and again after return to baseline with removal of the added weight. Alveolar and tracheal $\left|\mathrm{P}_{\mathrm{aw}}\right|$ and $\overline{\mathrm{P}}_{\mathrm{aw}}$ values were averaged across data sets for each weight. In one animal, after successful placement of the first capsule, a second capsule was placed on the middle lobe and measurements were taken with a 1 -g weight.

For these studies, the HFOV settings were chosen to obtain normal blood gas values. Ventilator frequency $(15 \mathrm{~Hz}), \mathrm{T}_{\mathrm{i}}(0.3)$, fraction of inspired oxygen (30\%), and mean airway pressure $(5$

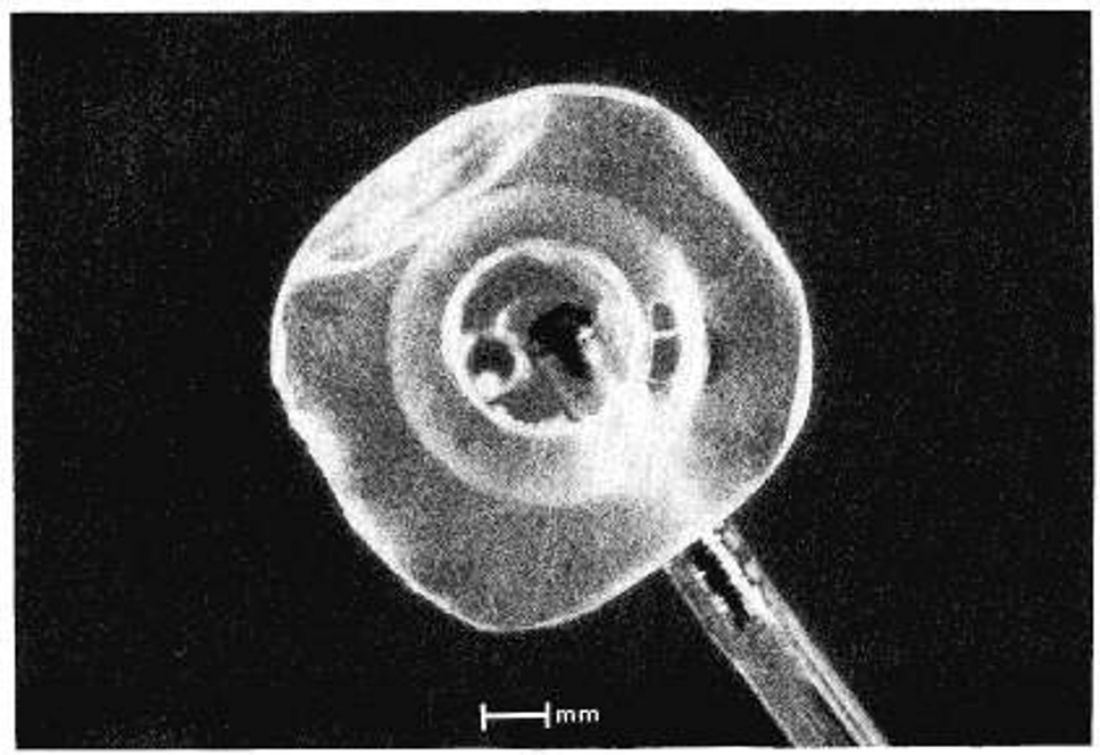

Fig. 1. Photo of the assembled low-mass pleural chamber and fiberoptic catheter tip transducer, which compose the modified alveolar capsule. Dimensions of the chamber are $2.9 \mathrm{~mm}$ inner diameter $\times 3.9 \mathrm{~mm}$ high with a total volume of $23 \mu \mathrm{L}$. Mass of the chamber and transducer is 430 mg. The capsule is applied to the exposed pleural surface with cyanoacrylate. 
$\mathrm{cm} \mathrm{H}_{2} \mathrm{O}$ ) were held constant, whereas ventilation was controlled by small adjustments in ventilator pressure amplitude.

HFOV Experiments. Animal model. Nine Pasteurella-free New Zealand White adult rabbits were given initial sedation and anesthesia and prepared for thoracotomy as described above. These animals were connected to a pressure-limited, time-cycled infant ventilator (Bear Cub, Bourns Inc., Riverside, CA) on a fraction of inspired oxygen of 0.28 with rate and pressure adjusted to yield a normal arterial blood gas ( $\mathrm{pH} 7.33-7.73$, arterial $\mathrm{CO}_{2}$ pressure 11-28 torr, arterial $\mathrm{O}_{2}$ pressure 79-108 torr) (17).

A right parasternal thoracotomy was accomplished with exposure of the right middle and upper lobes. In four animals, a pleural capsule was applied to the right upper lobe, and in five animals the capsule was placed on the right middle lobe. The animals received pancuronium bromide and ketamine throughout the experiment as noted previously.

Pressure measurements. Proximal airway pressure was measured via a pressure port at the endotracheal tube connector (Respiratory Support Products, Inc., Newport Beach, CA) using a $\pm 150 \mathrm{~cm} \mathrm{H}_{2} \mathrm{O}$ pressure transducer (model MP45, Validyne).

Airway pressure within the trachea was measured with the already described stainless steel pressure monitoring tube, and alveolar pressures with the low-mass pleural capsule.

All three pressure signals were monitored simultaneously and recorded as above. Representative waveforms were averaged over 2-s epochs for $\overline{\mathrm{P}}_{\mathrm{aw}}$. Cycle peak and trough airway pressures were determined from which $\left|\mathrm{P}_{\mathrm{aw}}\right|$ was calculated and averaged over the epoch.

Experimental protocol. When the animal was stable after surgery and pleural capsule placement, ventilation was switched from conventional ventilation to HFOV. By design, each animal was randomly sequenced through six combinations of frequency $(10,15,20 \mathrm{~Hz})$ and $T_{i}(0.3,0.5)$. At each new ventilator setting combination, proximal $\left|\mathrm{P}_{\mathrm{aw}}\right|$ and $\overline{\mathrm{P}}_{\mathrm{aw}}$ were adjusted to yield normal rabbit arterial blood gas values. After verification of the arterial blood gas, measurements were recorded from each of the three measurement sites and then the sequence was repeated for the next combination of $T_{i}$ and frequency. Throughout our protocol, we interspersed maneuvers for confirming the accuracy of our alveolar measurements, frequently discontinuing oscillations and placing the ventilator in a constant pressure mode to document that proximal and capsule steady-state pressures were identical.

Data analysis. The effect of added mass on alveolar and tracheal pressures was tested using one-way analysis of variance with statistical significance considered to be achieved at the $p<$ 0.05 level.

To test the effect of frequency, $T_{i}$, and measurement site on $\left|\mathrm{P}_{\mathrm{aw}}\right|$ and $\overline{\mathrm{P}}_{\mathrm{aw}}$, we first performed a multifactorial analysis of variance to evaluate for main effects $(p<0.05)$. Where no effect was seen, data were subsequently reduced on that parameter. Where significant effects were noted, more detailed analyses were performed. These included one-way analysis of variance with Fisher least significant difference comparisons for the evaluation of between-site pressures for each group and $T_{i}$ value. Also performed was a two-way analysis of variance (groups versus site) at each $T_{i}$ setting with post hoc $t$ tests using a Bonferonni correction for three comparisons $(p<0.017)$. These tests were performed to identify specific sites where airway pressures differed between the two animal groups. Similarly, a two-way analysis of variance was performed $\left(T_{i}\right.$ versus site) for each group with similar post hoc tests to determine the effect of $T_{i}$ on $\left|P_{a w}\right|$ and $\overline{\mathbf{P}}_{\mathrm{aw}}$.

\section{RESULTS}

Pressure measurement systems. The frequency characteristics of the tracheal and alveolar measurement systems were evaluated and compared with the reference transducer. For the tracheal pressure measurement system, the response was flat to $80 \mathrm{~Hz}$
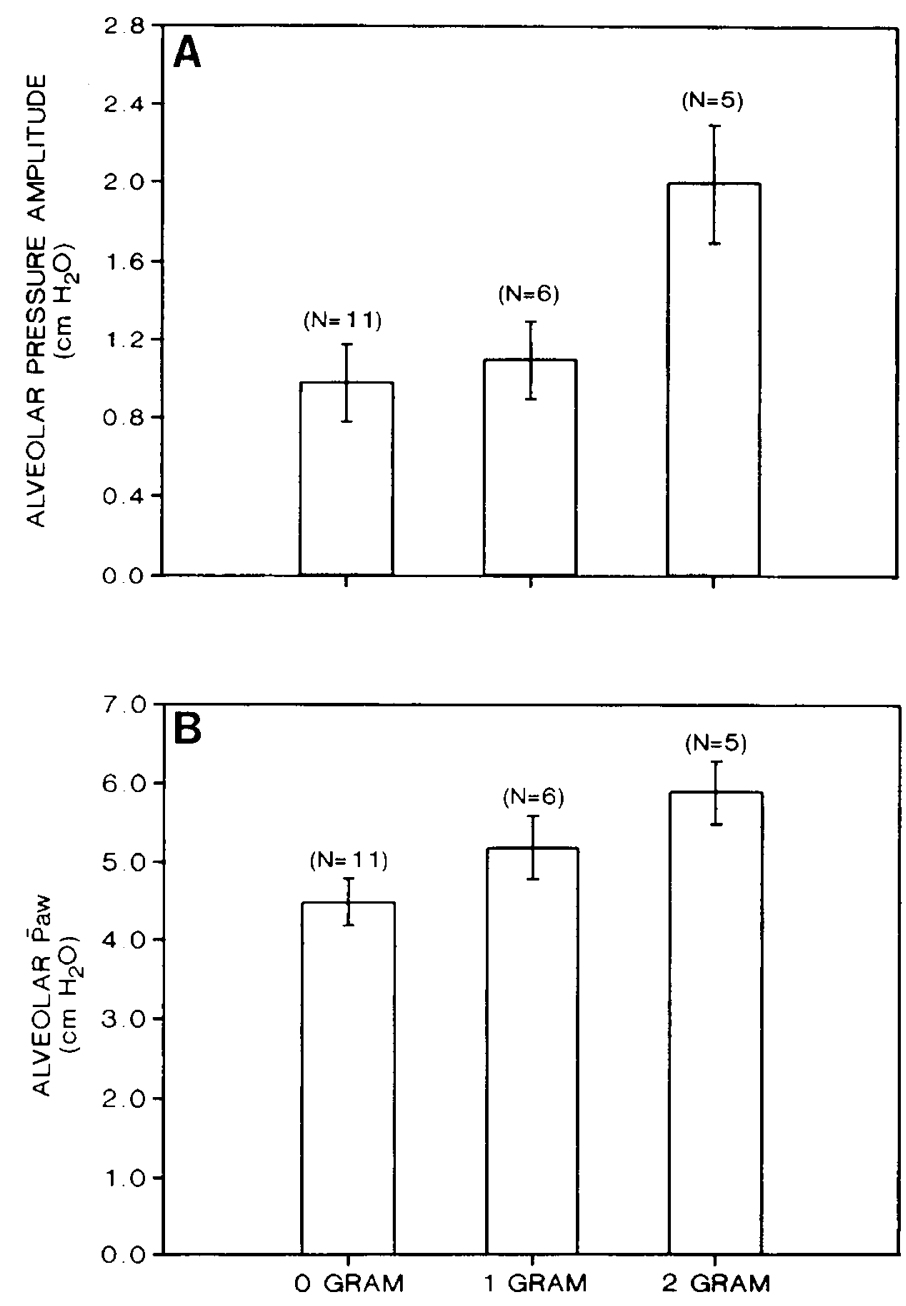

Fig. 2. Pressure amplitude $\left(\left|\mathrm{P}_{\mathrm{aw}}\right|\right.$, top panel) and alveolar mean pressure ( $\left(\overline{\mathrm{P}}_{\mathrm{aw}}\right.$, bottom panel $)$ as a function of 1 and $2 \mathrm{~g}$ weight added to the capsule measurement system during HFOV. HFOV settings were: frequency $=15 \mathrm{~Hz}, \mathrm{~T}_{\mathrm{i}}=0.3$, proximal $\overline{\mathrm{P}}_{\mathrm{aw}}=5 \mathrm{~cm} \mathrm{H} \mathrm{H}_{2} \mathrm{O}$. Capsule was placed on the right middle lobe. Data for the $0-\mathrm{g}$ column includes both baseline values and values recorded after removal of the weights. The increases in alveolar $\left|\mathrm{P}_{\mathrm{aw}}\right|$ and $\overline{\mathrm{P}}_{\mathrm{aw}}$ were statistically significant $(p<0.05$, analysis of variance).

Table 1. Multifactorial analysis of variance*

\begin{tabular}{llllll}
\hline & \multicolumn{2}{c}{$\left|\mathrm{P}_{\mathrm{aw}}\right|$} & & \multicolumn{2}{c}{$\overline{\mathrm{P}}_{\mathrm{aw}}$} \\
\cline { 2 - 3 } \cline { 5 - 6 } Main effects & $F$ & $p$ & & $F$ & \multicolumn{1}{c}{$p$} \\
\hline $\mathrm{T}_{\mathrm{i}}(0.3,0.5)$ & 5.0 & 0.06 & & 12.9 & 0.0088 \\
$\begin{array}{c}\text { Frequency }(10,15,20 \\
\quad \text { Hz) }\end{array}$ & 2.1 & 0.16 & & 0.5 & 0.62 \\
$\begin{array}{c}\text { Site (proximal, tracheal, } \\
\text { alveolar) }\end{array}$ & 91.9 & 0.0000 & & 17.4 & 0.0002 \\
\hline
\end{tabular}

* Results of a multifactorial analysis of variance to evaluate for main interactions between changes in $\left|\mathrm{P}_{\mathrm{aw}}\right|$ and $\overline{\mathrm{P}}_{\mathrm{aw}}$ and experimental conditions of $T_{i}$, frequency, and measurement site. Frequency, per se, did not statistically contribute to variations in either $\left|\mathrm{P}_{\mathrm{aw}}\right|$ or $\overline{\mathrm{P}}_{\mathrm{aw}}$.

and 2.5 decibels down at $100 \mathrm{~Hz}$. The phase difference was $0^{\circ}$ up to $50 \mathrm{~Hz}$ and less than $10^{\circ}$ at $100 \mathrm{~Hz}$. For the alveolar pressure measurement system, the response was flat to greater than $40 \mathrm{~Hz}$ and 3 decibels down at $100 \mathrm{~Hz}$. There was a linear phase shift with respect to the reference transducer that was $150^{\circ}$ at $100 \mathrm{~Hz}$. The transfer functions for the simulated in situ capsule system were the same as those without the punctured pleural surface. These results indicate that the amplitude response of both measurement systems was adequate for the ventilatory parameters 
0.3 Fractional Inspiratory Time

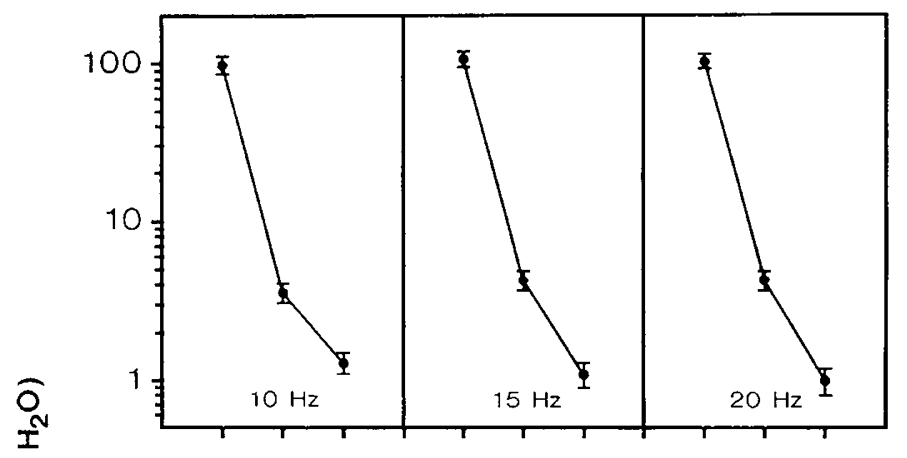

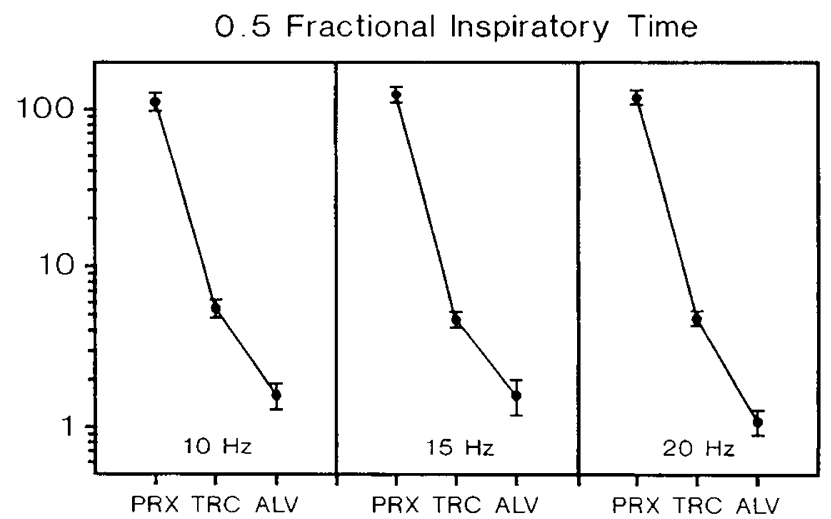

AIRWAY SITE

Fig. 3. Logarithmic plot of $\left|P_{a w}\right|$ at proximal, tracheal, and alveolar measurement sites, displayed by frequency $(10,15$, and $20 \mathrm{~Hz})$ and by $T_{i}(0.3$ and 0.5$)$. Because analysis of variance indicated no between-group differences, data for animals in the middle lobe and upper lobe capsule groups have been combined and plotted (solid circles). Values are mean \pm SEM. Levels of statistical significance for several different comparisons are shown in Tables 2 and 3 .

used in this study. The phase shift of the alveolar measurement system appeared to be inherent in the fiber optic transducer/ amplifier itself and was not a function of the capsule per se. No measurements were taken during the experiments that involved phase comparisons.

The amplitude of the time-varying capsule pressure, $\left|\mathrm{P}_{\mathrm{aw}}\right|$, was significantly affected by increasing the capsule mass $(p<$ $0.05)$. Alveolar pressure amplitude increased from $0.96 \pm 0.19$ to $1.15 \pm 0.26$, to $1.98 \pm 0.29 \mathrm{~cm} \mathrm{H}_{2} \mathrm{O}$ as capsule mass was increased by 1 and $2 \mathrm{~g}$, respectively (Fig. $2 a$ ). Tracheal $\left|\mathrm{P}_{\mathrm{aw}}\right|$ was unaffected by capsule mass.

With the $1-\mathrm{g}$ added mass, capsule $\overline{\mathrm{P}}_{\mathrm{aw}}$ increased by $16 \%$ compared with the baseline pressure. When the 2-g mass was added, $\overline{\mathrm{P}}_{\mathrm{aw}}$ increased by $32 \%$. This effect of increasing capsule mass on $\overline{\mathbf{P}}_{\mathrm{aw}}$ was statistically significant $(p<0.05)$, and is shown graphically in Figure $2 b$. When the mass was removed, capsule $\overline{\mathrm{P}}_{\mathrm{aw}}$ returned to the original value. There was no effect on tracheal $\overline{\mathrm{P}}_{\mathrm{aw}}$ as capsule mass was increased.

HFOV experiments. Upper and middle lobe alveolar mechanics were evaluated in separate animal groups whose ventilator parameters were adjusted to normalize blood gas values. The results of the multifactorial analysis of variance are presented in Table 1. Ventilator frequency appeared to contribute little to the variation in either $\left|\mathrm{P}_{\mathrm{aw}}\right|$ or $\overline{\mathrm{P}}_{\mathrm{aw}}$. However, effects are noted for the interaction of $\mathrm{T}_{\mathrm{i}}$ on $\overline{\mathrm{P}}_{\mathrm{aw}}$, and for airway site on the variability in both $\mathrm{P}_{\mathrm{aw}}$ and $\left|\overline{\mathrm{P}}_{\mathrm{aw}}\right|$. The relationships between $\mathrm{T}_{\mathrm{i}}$, frequency, airway measurement site, and airway pressures are presented in Figures 3 and 4 . More detailed analyses are exhibited in Tables 2 and 3, where the data have been compressed across frequencies, justified due to the lack of effect of frequency on $\left|\mathrm{P}_{\mathrm{aw}}\right|$ or $\overline{\mathrm{P}}_{\mathrm{aw}}$.

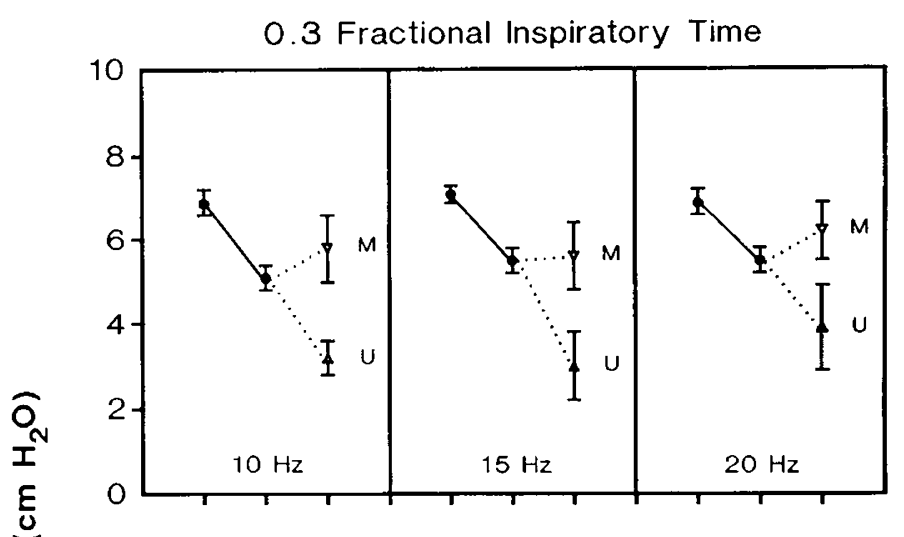

0.5 Fractional Inspiratory Time

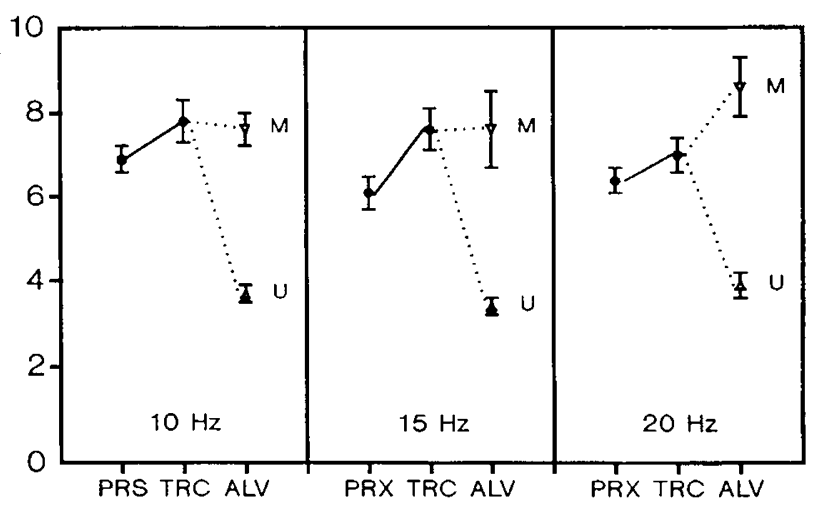

AIRWAY SITE

$M=$ middle lobe

$U=$ upper lobe

Fig. 4. $\overline{\mathrm{P}}_{\mathrm{aw}}$ at proximal, tracheal, and alveolar measurement sites, displayed by frequency $(10,15$, and $20 \mathrm{~Hz})$ and by $T_{i}(0.3$ and 0.5$)$. Analysis of variance indicated no between-group differences at proximal and tracheal sites, so data for animals in the middle lobe and upper lobe capsule groups have been combined and plotted (solid circles). Values are mean \pm SEM. Differences in alveolar measurements are displayed as open triangles ( $\triangle=$ upper lobe group, $\nabla=$ middle lobe group). Levels of statistical significance for several different comparisons are shown in Tables 2 and 3.

$\left|P_{a w}\right|$. The behavior of the dynamic component of the highfrequency oscillations is shown in Figure 3. There were no differences at any site between groups (Table 3), so group values were combined and plotted. Within each group, increasing $T_{i}$ from 0.3 to 0.5 did not cause significant changes in $\left|\mathrm{P}_{\mathrm{aw}}\right|$ at any site (Table 3). The amplitude of the pressure oscillations, $\left|P_{a w}\right|$, followed a consistent pattern. We found a progressive attenuation in $\left|\mathrm{P}_{\mathrm{aw}}\right|$, moving from proximal to trachea to alveolus (Table 2, $p<0.0001$ ). This effect was true for both values of $T_{i}$. Tracheal and alveolar $\left|\mathrm{P}_{\mathrm{aw}}\right|$ were statistically smaller than $\left|\mathrm{P}_{\mathrm{aw}}\right|$ measured proximally, although post hoc comparisons did not show alveolar $\left|\mathrm{P}_{\mathrm{aw}}\right|$ to be less than tracheal.

$\bar{P}_{a w}$. The values for $\overline{\mathrm{P}}_{\mathrm{aw}}$ by frequency and site are depicted in Figure 4. Because no between-group differences were seen in $\overline{\mathrm{P}}_{\mathrm{aw}}$ in proximal and tracheal measurements (Table 3 ), these values were combined and plotted. Significant changes across sites are seen in each animal group at each $T_{i}$ value (Table 2). At $T_{i}=$ 0.3 , tracheal $\overline{\mathrm{P}}_{\mathrm{aw}}$ is less than proximal $\overline{\mathrm{P}}_{\mathrm{aw}}$, whereas at $\mathrm{T}_{\mathrm{i}}=0.5$ tracheal $\overline{\mathrm{P}}_{\mathrm{aw}}$ exceeds proximal $\overline{\mathrm{P}}_{\mathrm{aw}}$. Alveolar $\overline{\mathrm{P}}_{\mathrm{aw}}$ is always less than tracheal, and always less than proximal $\overline{\mathrm{P}}_{\mathrm{aw}}$ in the upper lobe; however, in the middle lobe, alveolar $\overline{\mathrm{P}}_{\mathrm{aw}}$ is equivalent to or greater than proximal $\overline{\mathrm{P}}_{\mathrm{aw}}$, depending on whether $\mathrm{T}_{\mathrm{i}}=0.3$ or 0.5 .

Upper lobe alveolar $\overline{\mathrm{P}}_{\mathrm{aw}}$ was less than middle lobe alveolar $\overline{\mathrm{P}}_{\mathrm{aw}}$ at both $T_{i}=0.3$ and $T_{i}=0.5$. Additionally, increasing $T_{i}$ from 
0.3 to 0.5 caused significant increases in tracheal $\overline{\mathrm{P}}_{\mathrm{aw}}$ in both groups of animals. Finally, this same change in $T_{i}$ caused an increase in middle lobe alveolar $\overline{\mathrm{P}}_{\mathrm{aw}}$, but no such change was seen in the upper lobe.

\section{DISCUSSION}

Our study demonstrates the measurement of alveolar pressures using a system of reduced size and mass compared with capsule systems that have been previously reported $(2,3,5,6,9,18)$. The system is shown by in vitro testing to have excellent signal fidelity with no loss of resolution or sensitivity within the frequency range of potential high-frequency ventilation. However, use of the capsule system for real time comparison of different airway sites or different pleural surface locations would require compensation for a phase difference of $15-20^{\circ}$ at $15 \mathrm{~Hz}$.

Previous reports using similar systems to estimate alveolar pressures have used pleural capsules weighing from 3 to $9 \mathrm{~g}$ (1$3,5,6,9,18)$. In contrast, we have used a capsule system weighing considerably less $(430 \mathrm{mg}$ ). Because the heavier capsules were also larger than those used in our studies, it is possible that point forces on the visceral pleura were lower due to greater surface contact area. Calculated surface forces developed by the system described in this paper are $\left(0.43 \mathrm{~g} \times 980.7 \mathrm{~cm} / \mathrm{s}^{2}\right) /\left(0.40 \mathrm{~cm}^{2}\right)=$ 1044 dynes $/ \mathrm{cm}^{2}$. Based on data available by Fredberg et al. (9) and McNamara et al. (5), we calculated the surface forces for the 3 -g capsule/transducer system used in their studies to be $(3 \mathrm{~g} \times$ $\left.980.7 \mathrm{~cm} / \mathrm{s}^{2}\right) /\left(1.5 \mathrm{~cm}^{2}\right)=1961 \mathrm{dynes} / \mathrm{cm}^{2}$, or $88 \%$ higher.

The lighter system used in our experiments would necessarily present a lower mechanical load to the lung parenchyma. This is in agreement with our observations that even slight pressures externally applied to the capsule caused marked elevations in the capsule pressure. In fact, we found that addition of a $2-\mathrm{g}$ weight caused mean alveolar pressures to increase by $32 \%$.

The mechanism by which pleural compression might cause an increase in capsule pressure is unclear. Tissue compression may cause terminal airway narrowing or valving resulting in local gas trapping. This in turn could result in an increase in local alveolar volume and an increase in the pressure measured in the capsule. The same mechanism could also explain the increase in alveolar pressure amplitude that we saw with increasing capsule mass. As parenchymal compression increased, closing off neighboring connecting alveolar spaces, local compliance would decrease, causing higher pressure swings for equivalent volume fluctuations. The reports by Frantz and Close (1) and Fredberg et al. (9) noted that alveolar pressure measured at the capsule was not altered by increasing capsule mass from $3 \mathrm{~g}$ up to $9 \mathrm{~g}$. These differences with our study may be related to different lung structure characteristics of the two animal models. They may also be related to other protocol differences, such as the number, diameter, and depth of pleural punctures. The geometry of these access holes is unknown in relation to their penetration below the pleura into alveolar sacs or distal airways. The creation of small bronchiolar-pleural-capsule fistulae could be possible and would increase the likelihood of measuring distal airway pressure changes rather than alveolar pressure changes. One would expect relatively little effect of small pleural loads on the pressure in such airways.

The experiments using this low-mass capsule system to measure alveolar pressure during HFOV were very revealing. These data demonstrate that upper lobe alveolar $\overline{\mathrm{P}}_{\mathrm{aw}}$ measured in one group of animals is lower compared with a second group of animals where alveolar $\overline{\mathrm{P}}_{\mathrm{aw}}$ was measured in the middle lobe during HFOV. Furthermore, the upper lobe alveolar pressures were lower than pressures measured in the trachea, and these findings were independent of $T_{i}$ or frequency. $T_{i}$, however, did have a profound influence on $\overline{\mathrm{P}}_{\mathrm{aw}}$ in the trachea and in the middle lobe alveolus, causing these pressures to increase as $T_{i}$ increases. In addition $\left|P_{a w}\right|$ was significantly attenuated during 
Table 3. Differences between groups and effect of inspiratory time on airway pressures*

\begin{tabular}{|c|c|c|c|c|c|c|c|c|c|c|}
\hline & \multicolumn{5}{|c|}{$\left|\mathrm{P}_{\mathrm{aw}}\right|$} & \multicolumn{5}{|c|}{$\overline{\mathrm{P}}_{\mathrm{aw}}$} \\
\hline & \multicolumn{2}{|c|}{$\begin{array}{l}\text { Two-way } \\
\text { ANOVA }\end{array}$} & \multicolumn{3}{|c|}{ Post hoc $t$ test } & \multicolumn{2}{|c|}{$\begin{array}{l}\text { Two-way } \\
\text { ANOVA }\end{array}$} & \multicolumn{3}{|c|}{ Post hoc $t$ test } \\
\hline & $F$ & $p$ & $p$ PRX & $p \mathrm{TRC}$ & $p \mathrm{ALV}$ & $F$ & $p$ & $p$ PRX & $p$ TRC & $p \mathrm{ALV}$ \\
\hline & \multicolumn{7}{|c|}{ (between groups) } & \multicolumn{3}{|c|}{ (between groups) } \\
\hline $\begin{array}{c}\text { Group } \times \text { site } \\
0.3 \mathrm{~T}_{\mathrm{i}} \\
0.5 \mathrm{~T}_{\mathrm{i}}\end{array}$ & $\begin{array}{l}0.6 \\
1.0\end{array}$ & $\begin{array}{l}0.5793 \\
0.4019\end{array}$ & $\begin{array}{l}0.2396 \\
0.1204\end{array}$ & $\begin{array}{l}0.8888 \\
0.3943\end{array}$ & $\begin{array}{l}0.6826 \\
0.6915\end{array}$ & $\begin{array}{l}10.0 \\
35.3\end{array}$ & $\begin{array}{l}0.0020 \dagger \\
0.0000 \dagger\end{array}$ & $\begin{array}{l}0.0529 \\
0.0871\end{array}$ & $\begin{array}{l}0.9440 \\
0.3060\end{array}$ & $\begin{array}{l}0.0003 \ddagger \\
0.0000 \ddagger\end{array}$ \\
\hline & \multicolumn{7}{|c|}{ (between $T_{i}$ ) } & \multicolumn{3}{|c|}{ (between $T_{i}$ ) } \\
\hline $\mathrm{T}_{\mathrm{i}} \times$ site & & & & & & & & & & 05258 \\
\hline $\begin{array}{l}\text { Upper lobe group } \\
\text { Middle lobe group }\end{array}$ & $\begin{array}{l}1.2 \\
2.1\end{array}$ & $\begin{array}{l}0.2969 \\
0.1330\end{array}$ & $\begin{array}{l}0.2601 \\
0.1472\end{array}$ & $\begin{array}{l}0.1140 \\
0.1890\end{array}$ & $\begin{array}{r}0.1154 \\
0.2286\end{array}$ & $\begin{array}{r}13.3 \\
9.7\end{array}$ & $0.0002 \uparrow$ & 0.1072 & 0.0004 & $0.0013 \ddagger$ \\
\hline
\end{tabular}

* Results of two-way analysis of variance examining for differences in mean values between groups at each measurement site for each $\mathrm{T}_{\mathrm{i}}$, and the effect within each group at each measurement site with changing $\Upsilon_{\mathrm{j}}$ from 0.3 to 0.5 . The analysis of variance was considered significant at the $p<$ 0.05 level. Post hoc $t$ tests were done to identify site-specific differences. A Bonferroni correction for three comparisons was used to adjust the acceptable significance level to $p<0.017$. Abbreviations: ANOVA, analysis of variance; PRX, proximal; TRC, tracheal; ALV, alveolar.

$\dagger$ Significant $(p<0.05)$.

$\ddagger$ Significant $(p<0.017)$.

transmission across the endotracheal tube, and decreased further when measured at the alveolus.

The attenuation of $\left|\mathrm{P}_{\mathrm{aw}}\right|$ across the endotracheal tube is a complex filtering process, a function of endotracheal tube physical characteristics and pressure waveform frequency composition (19). Considering the noisy character of the proximal pressure waveform for this type of HFOV device, it was not surprising that endotracheal tube filtering was significant. We found a $97 \%$ decrement in amplitude in the trachea. Furthermore, we measured an additional $75 \%$ decrease in $\left|\mathrm{P}_{\mathrm{aw}}\right|$ between the trachea and alveolus, similar to that predicted by Niederer et al. (20). Under the physiologic conditions of this experiment, we did not see resonant amplification in the alveolus (i.e. alveolar $\left|\mathrm{P}_{\mathrm{aw}}\right|>$ tracheal $\left.\left|\mathrm{P}_{\mathrm{aw}}\right|\right)$ at the frequencies tested, as previously reported in isolated lungs for small-amplitude oscillations (3, 9). Although the magnitude of alveolar $\left|\mathrm{P}_{\mathrm{aw}}\right|$ was always small in a clinical sense, being on the order of $1 \mathrm{~cm} \mathrm{H}_{2} \mathrm{O}$, it still probably fell in the realm of nonlinear behavior for large-amplitude oscillations and, thus, the observations of Allen et al. (3) and Fredburg et al. (9) may not apply. On the other hand, if cyclic stretch in a poorly compliant lung is a factor in the etiology of pulmonary injury, then HFOV, as demonstrated by relatively low amplitude alveo$\operatorname{lar}\left|\mathrm{P}_{\mathrm{aw}}\right|$ in this model, should be an ideal mode of ventilation to reduce or prevent baroinjury.

We found that $\overline{\mathrm{P}}_{\mathrm{aw}}$ was always less in the upper lobe than in the middle lobe. Similar findings have been reported in excised dog lungs (4). These results imply that the interlobe heterogeneity is neither species-specific nor absent in the intact animal and confirm that preferential distention of the basilar region and regional volume distribution inhomogeneities occur in lungs ventilated with HFOV. Interlobe heterogeneity is known to be position dependent (10), which could explain our findings and perhaps those of others $(2,4)$. The mean pressure inhomogeneity, however, may also be a function of airway geometry (4). If so, it is reasonable to expect intralobar heterogeneity in alveolar $\overline{\mathbf{P}}_{\mathrm{aw}}$ as well, although this has yet to be demonstrated (11).

Airway pressures varied considerably in response to changes in $T_{i}$ during HFOV. We found that as $T_{i}$ increased from 0.3 to 0.5 , tracheal and middle lobe alveolar $\overline{\mathrm{P}}_{\mathrm{aw}}$ increased at each frequency tested. This was a dynamic phenomenon that disappeared when the animal was sighed or placed on continuous positive airway pressure. From a clinical point of view, this observation has great significance because there was no noticeable change in pressures at the proximal site, where ventilator pressure monitoring measurements are commonly accomplished. Proper clinical management requires using proximal airway pressures to estimate tracheal and alveolar pressures. Our study indicates that although this might be safe when $T_{i}=0.3$, the situation becomes less predictable as inspiratory time approaches expiratory time.

In general, increases in tracheal and alveolar pressures, such as those seen in our experiments at $T_{i}=0.5$, occur when expired volume is less than the inspired volume. When the expiratory time is decreased (i.e. $T_{i}$ increases while the ventilation frequency remains constant), the average expiratory flow over one cycle must increase to produce the same expired volume in the shorter allowed time. If some mechanism prevents the required increase in flow, increased lung volumes and pressures will result.

This could occur if the pressure gradient between the alveoli and ventilator is too small to provide the necessary increase in flow. During conventional ventilation, this pressure gradient is the difference between alveolar pressure and continuous distending pressure. In the oscillatory ventilator, this pressure is the difference between alveolar pressure and the pressure created within the ventilator during expiration, which can be well below atmospheric pressure. Thus, the oscillator can create much larger pressure gradients, and much larger flows. The larger flows make it less likely that the oscillator, a device with an "active" expiration phase, would cause an increase in alveolar and tracheal pressure when $T_{i}$ is increased, compared with ventilators that rely solely on passive expiration (21). Our data, however, would suggest that HFOV can also demonstrate this effect, but at a relatively low absolute level. Higher alveolar pressures would contribute to increasing lung volume. Lung hyperinflation during HFOV has been documented in several animal models (22-24) and in humans (12) within frequency ranges similar to those in our study $(10-20 \mathrm{~Hz})$.

Although we did not measure lung volume, we provide suggestive evidence that at $T_{i}=0.3$ lung hyperinflation secondary to HFOV is unlikely, inasmuch as alveolar mean pressure is less than proximal mean pressure.

Expiratory resistance exceeding inspiratory resistance is a second mechanism that could reduce expiratory flow. Viscous and turbulent flow dissipation has been shown to depend on local airway compliance (25), which varies with inspiration and expiration. Differences in inspiratory and expiratory resistance based on geometry have also been demonstrated (26), and this factor may also play a role.

The increases in tracheal pressure measured when $T_{i}=0.5$ may be due to an effect of the endotracheal tube. When $T_{i}=$ 0.3 , the mean flow (velocity) through the endotracheal tube during inspiration must be twice that during expiration if the 
inspiratory and expiratory volumes are to be equal. However, the resistance varies as the square of the mean velocity (27), so that doubling the mean velocity must result in an inspiratory resistance that is considerably higher than the expiratory resistance. The effect of this large inequality between inspiratory and expiratory pressure drop on flow, when averaged over the ventilator cycle, results in a tracheal mean pressure that is lower than the proximal mean pressure. This is demonstrated in our results shown in Figure 4. However, when $T_{i}$ is increased to 0.5 , the mean velocities become equal. This leads to an increase in the mean tracheal pressure compared with when $T_{i}=0.3$. Figure 4 also shows this expected increase in tracheal pressure. That tracheal mean pressures actually exceeded proximal mean pressures at $T_{i}=0.5$ implies some degree of inspiratory/expiratory asymmetry in the oscillator pressure waveform, or that $\mathrm{T}_{\mathrm{i}}$, although indicated as 0.5 , may have slightly exceeded 0.5 , causing operation at a reversed inspiratory to expiratory ratio.

If one or more of these mechanisms operates during HFOV, then a residual of the inspired volume remains in the airways, causing tracheal and alveolar $\overline{\mathrm{P}}_{\mathrm{aw}}$ to increase. Once tracheal $\overline{\mathrm{P}}_{\mathrm{aw}}$ increases to a level that establishes a sufficient expiratory pressure gradient, inspired and expired volumes will be equal and pressures will stabilize at a new equilibrium level.

In summary, we have studied the effect of changes in frequency and $T_{i}$ during HFOV on the transmission of pressure through the airways to the alveolus. Using a low-mass alveolar capsule in a physiologic open-chest rabbit model, we have noted $\overline{\mathrm{P}}_{\mathrm{aw}}$ inhomogeneity between upper and middle lobes and an effect of $T_{i}$ on tracheal and alveolar pressures. Ventilator frequency appeared to have little effect on pressure transmission within the realm of ventilator parameters used in this study. There was marked attenuation of the oscillatory amplitude over the entire airway. Of special clinical importance is the fact that changes in airway pressure in the trachea or in the alveolus were not reflected in proximal pressure measurement within the ventilator circuit, the most common location for clinical monitoring.

Acknowledgments. The authors thank Joe Guerra, R.T., for his indispensable technical assistance and Dr. K. Nose, Tokyo Womens Hospital, Tokyo, Japan for his collaboration.

\section{REFERENCES}

1. Frantz ID, Close RH 1985 Alveolar pressure swings during high frequency ventilation in rabbits. Pediatr Res 19:162-166

2. Allen JL, Frantz ID, Fredberg JJ 1985 Regional alveolar pressure during periodic flow. J Clin Invest 76:620-629

3. Allen JL, Fredberg JJ, Keefe DM, Frantz ID 1985 Alveolar pressure magnitude and asynchrony during high-frequency oscillations of excised rabbit lungs. Am Rev Respir Dis 132:343-349

4. Allen JL, Frantz ID, Fredberg JJ 1987 Heterogeneity of mean alveolar pressure during high-frequency oscillations. J Appl Physiol 62:223-228
5. McNamara JJ, Castile RG, Glass GM, Fredberg JJ 1987 Heterogeneous lung emptying during forced expiration. J Appl Physiol 63:1648-1657

6. Fredberg JJ, Ingram Jr RH, Castile RG, Glass GM, Drazen JM 1985 Nonhomogeneity of lung response to inhaled histamine assessed with alveolar capsules. J Appl Physiol 58:1914-1922

7. Perez Fontan JJ, Heldt GP, Gregory GA 1986 Mean airway pressure and mean alveolar pressure during high-frequency jet ventilation in rabbits. $\mathrm{J} A \mathrm{Apl}$ Physiol 61:456-463

8. Bryan AC, Slutsky AS 1986 Lung volume during high frequency oscillation. Am Rev Respir Dis 133:928-930

9. Fredberg JJ, Keefe DH, Glass GM, Castile RG, Frantz ID 1984 Alveolar pressure nonhomogeneity during small-amplitude high-frequency oscillation. J Appl Physiol 57:788-800

10. Simon BA, Weinmann GG, Mitzner W 1984 Mean airway pressure and alveolar pressure during high-frequency ventilation. J Appl Physiol 57:10691078

11. Warner DO, Hyatt RE, Rehder K 1988 Inhomogeneity during deflation of excised canine lungs. I. Alveolar pressures. J Appl Physiol 65:1757-1768

12. Saari AF, Rossing TH, Solway J, Drazen JM 1984 Lung inflation during highfrequency ventilation. Am Rev Respir Dis 129:333-336

13. Brusasco V, Beck KC, Crawford M, Rehder K 1986 Resonant amplification of delivered volume during high frequency ventilation. J Appl Physio 60:885-892

14. The HIFI Study Group 1989 High-frequency oscillatory ventilation compared with conventional mechanical ventilation in the treatment of respiratory failure. N Engl J Med 320:88-93

15. Clark RH, Gerstmann DR, Null DM, Yoder BA, Cornish JD, Glasier CM Ackerman NB, Bell RE, deLemos RA 1986 Pulmonary interstitial emphysema treated by high-frequency oscillatory ventilation. Crit Care Med 14:926-930

16. Jackson AC, Vinegar A 1979 A technique for measuring frequency response of pressure, volume and flow transducers. J Appl Physiol 47:462-467

17. Strauss J, Beran AV, Baker R, Boydston L, Reyes-Sanchez JL 1971 Effect of hemorrhagic shock on renal oxygenation. Am J Physiol 221:1545-1550

18. Frantz ID, Close RH 1985 Elevated lung volume and alveolar pressure during jet ventilation of rabbits. Am Rev Respir Dis 131:134-138

19. Dorkin HL, Stark AR, Werthammer JW, Fredberg JJ 1983 Respiratory system impedance from 4 to $40 \mathrm{~Hz}$ in paralyzed intubated infants with respiratory disease. J Clin Invest 72:903-910

20. Niederer P, Spahn D, Schmid E, Lukenheimer PP 1988 Propagation and damping of flow disturbances in the bronchial tree in high-frequency ventilation. Phys Med Biol (suppl 1) 33:219

21. Bancalari A, Gerhardt T, Bancalari E, Suguihara C, Hehre D, Reifenberg L Goldberg RN 1987 Gas trapping with high-frequency ventilation: jet versus oscillatory ventilation. J Pediatr 110:617-622

22. Cha EJ, Chow E, Chang HK, Yamashiro SM 1988 Lung hyperinflation in isolated dog lungs during high-frequency oscillation. J Appl Physiol 65:11721179

23. Kolton M, Cattran CB, Kent G, Volgyesi G, Froese AB, Bryan AC 1982 Oxygenation during high-frequency ventilation compared with conventional mechanical ventilation in two models of lung injury. Anesth Analg 61:323332

24. Schmid ER, Knopp TJ, Rehder K 1981 Intrapulmonary gas transport and perfusion during high-frequency oscillation. J Appl Physiol 51:1507-1514

25. Lambert RK 1987 Bronchial mechanical properties and maximal expiratory flows. J Appl Physiol 62:2426-2435

26. Bush EH, Spahn DR, Niederer PF, Schmid ER 1989 Flow separation, an important mechanism in the formation of mean pulmonary pressure during high-frequency oscillation. J Biomech Eng 117:17-23

27. Reynolds DB 1982 Study expiratory flow-pressure relationship in a model of the human bronchial tree. J Biomech Eng 104:153-158 